\title{
Prenatal findings of 2q13 Duplication and Deletion: Further Evidence for Lack of Phenotypic-Genotype Correlation
}

\author{
Lu Li ${ }^{1}$, Xiuzhu Huang ${ }^{1}$, Mei Ye², Jieping Chen ${ }^{2}$, Zhipeng Zeng ${ }^{2}$, Hui Guo ${ }^{2}$, Qiuyan Liao $^{2}$, \\ Wenlong $\mathrm{Hu}^{2}$, Donge Tang ${ }^{2}$, and Yong Dai ${ }^{3}$ \\ ${ }^{1}$ Jinan University \\ ${ }^{2}$ Shenzhen People's Hospital \\ ${ }^{3}$ Southern University of Science and Technology
}

October 1, 2021

\begin{abstract}
2q13 CNV was associated with various diseases, with a lack of consensus. By CMA analysis, we found that four fetuses had deletion in the proximal region of $2 \mathrm{q} 13$, one had duplication, and one had duplication in the distal region of 2q13; however, they had variable outcomes.
\end{abstract}

\section{Prenatal findings of 2q13 Duplication and Deletion: Further Evidence for Lack of Phenotypic- Genotype Correlation}

$\mathrm{Lu} \mathrm{Li}^{1,2}$, Xiuzhu Huang ${ }^{1,2}$, Mei Ye ${ }^{2}$, Jieping Chen ${ }^{2}$, Zhipeng Zeng ${ }^{2}$, Hui Guo ${ }^{2}$, Qiuyan $\mathrm{Liao}^{2}$, Wenlong $\mathrm{Hu}^{* 2}$, Donge Tang*2, Yong Dai ${ }^{* 2}$

1 MOE Key Laboratory of Tumor Molecular Biology and Key Laboratory of Functional Protein Research of Guangdong Higher Education Institutes, Institute of Life and Health Engineering, College of Life Science and Technology, Jinan University, Guangzhou, Guangdong 510632, P.R. China

2 Clinical Medical Research Center, The Second Clinical Medical College of Jinan University, The First Affiliated Hospital of Southern University of Science and Technology, Shenzhen People's Hospital, Shenzhen, Guangdong 518020, P.R. China

\# Corresponding author:

Yong Dai, MD, PhD, Clinical Medical Research Center, The Second Clinical Medical College of Jinan University, The First Affiliated Hospital of Southern University of Science and Technology, Shenzhen People's Hospital, Shenzhen, Guangdong 518020, P.R. China. E-mail address:daiyong22@aliyun.com.

Donge Tang, PhD, Clinical Medical Research Center, The Second Clinical Medical College of Jinan University, The First Affiliated Hospital of Southern University of Science and Technology, Shenzhen People's Hospital, Shenzhen, Guangdong 518020, P.R. China. E-mail address:donge66@126.com

Wenlong $\mathrm{Hu}$, Clinical Medical Research Center, The Second Clinical Medical College of Jinan University, The First Affiliated Hospital of Southern University of Science and Technology, Shenzhen People's Hospital, Shenzhen, Guangdong 518020, P.R. China. E-mail address:369856967@qq.com

Funding:

This work was supported by Science and Technology Planning Project of Guangdong Province, China (No. 2017B020209001), the science and technology plan of Shenzhen (No. JCYJ20180305163846927). 


\section{KEY CLINICAL MESSAGE}

Through detailed prenatal screening and laboratory examinations, six fetuses were found to have deletions or duplications in chromosome 2q13, yet they have different disease phenotypes or consequences.

\section{ABSTRACT}

In previous studies, 2q13 CNV was associated with various diseases, with a lack of consensus. This study aimed to analyze the prenatal diagnosis and clinical presentation of fetuses with different deletions or duplications of 2q13. Detailed prenatal screening and laboratory examinations, including prenatal ultrasound diagnosis and amniocentesis, were performed, and genetic analysis was performed using multiplex ligationdependent probe amplification (MLPA) and chromosome microarray analysis (CMA). CMA analysis showed that four fetuses had deletion in the proximal region of 2q13, one had duplication, and one had duplication in the distal region of $2 \mathrm{q} 13$. Four fetuses had inherited copy number variation (CNV) from their parents; however, they had variable outcomes. Individuals with the same CNV of 2q13 may have different phenotypes or are unaffected; multiple individuals with the same deletion or duplication need to be evaluated to capture feature sets associated with that CNV. Genetic counseling and follow-up to the fetus's mother and family are essential. Genomic diseases' characteristics should be explained in detail when providing prenatal genetic counseling to mothers and their families.

KEYWORDS: chromosome 2q13; copy number variation; prenatal diagnosis; chromosomal microarray analysis

\section{INTRODUCTION}

Copy number variation (CNV) is the gain or loss of genomic material greater than $1 \mathrm{~KB}$ in the genome (Feuk, Carson, \& Scherer, 2006). Although CNV is common in normal people, in some cases, due to chromosomal rearrangement, it can affect certain genes' expression, leading to disease development (Giglio et al., 2001; Shaw \& Lupski, 2004). Deletion or duplication of the long arm of chromosome 2 have been reported to be associated with a variety of phenotypes, including orofacial clefting, developmental delay (DD), failure to thrive and dysmorphism (Wenger, Bleigh, \& Hummel, 2004; H. E. Yu et al., 2012). Not all CNVs have a pathogenic phenotype, and 2q13 CNVs have unknown clinical significance.

Compared with karyotype analysis, the chromosome microarray analysis (CMA) technique can detect small deletions and duplicates, effectively improving the detection rate of chromosomal abnormalities (Dhillon et al., 2014). It has rapidly replaced the standard G-band karyotype and has become an important diagnostic method for detecting chromosomal abnormalities in pregnancy products (Miller et al., 2010). Here, six new cases have been identified through the CMA with a 2q13 genomic imbalance and each with similar or different outcomes at prenatal diagnosis. Nevertheless, it may help identify these features early in the prenatal period for reference by parents and healthcare providers and monitor the condition or intervene promptly.

\section{MATERIALS AND METHODS}

The six probands with 2q13 duplication or deletion were seen in the Antenatal Diagnosis Center of Shenzhen People's Hospital. We collected clinical information on these cases. The following data were collected through medical record reviews: age, sex, gestational age and growth parameters at birth, parameters of obstetric examination during pregnancy, the risk of multiple genetic diseases and diagnostic CMA analysis, and multiplex ligation-dependent probe amplification (MLPA) assays were performed as part of their clinical evaluations.

Samples were taken from fetal exfoliated cells in amniotic fluid and lymphocytes of cord blood or parent peripheral blood. CMA was performed for each sample using a Cytoscan HD array (Affymetrix Inc., Santa Clara, CA, USA), and DNA was extracted according to the manufacturer's instructions. The annotation of the results was conducted in accordance with the Human Feb.2009 (GRCh37/hg19) Assembly.

\section{RESULTS}


Table 1 summarizes detailed clinical information for each fetus. The mothers ranged in age from 29 to 43 , and the average gestational age at the time of testing was about 21 weeks. Three fetuses were at high risk for Down syndrome. Three women had a history of spontaneous abortion, and two had a history of induced abortion. The mother of fetus 1 had two sons, one who died of neuroblastoma at age three and the other who died of intracranial hemorrhage at age 2 . The maternal and fetal outcomes of pregnancy were followed up (Table 2). All six cases were delivered successfully, with four fetuses delivered to term and one premature. All the fetuses were in the normal range of height and weight. Among them, the baby boy in case 4 was born with congenital hydrocephalus and congenital pulmonary cystadenomatous.

The UCSC database shows duplication or deletion regions and their involved genes in six fetuses (Figure 1 ). Five fetuses had deletions or duplications in the proximal or distal regions of $2 q 13$. Among them, four were deletions in the proximal region of $2 \mathrm{q} 13$, and one was duplication. A search of the Decipher database (https://decipher.sanger.ac.uk/) revealed that this region contained ten genes, of which 4 were OMIM genes: NPHP1 (OMIM: 607100), RGPD5 (OMIM: 612708), MALL (OMIM: 602022), RGPD6 (OMIM: 612709), and 1 was Morbid genes: NPHP1. Another fetus had a duplication of the distal region of 2q13, which the Decipher database showed contained 27 genes, including 8 OMIM genes: BUB1 (OMIM: 602452), ANAPC1 (OMIM: 608473), MERTK (OMIM: 604705), MIR4435-2HG (OMIM: 617144),BCL2L11 (OMIM: 603827), TMEM87B (OMIM: 617203),FBLN7 (OMIM: 611551), RGPD8 (OMIM: 602752), and 3 Morbid genes: BUB1, ANAPC1, MERTK . Figure 2 shows the chromosomal locations of duplication and deletion in six fetuses.

\section{Discussion}

\section{The deletion of the proximal region of $2 \mathrm{q} 13$}

One of the genes located in 2q13, NPHP1, has been reported to be closely associated with human disease. Nephronophthisis (NPHP) is a tubulo-interstitial, autosomal recessive cystic kidney disease, which is one of the most frequent genetic diseases causing end-stage renal disease (ESRD) in children and adolescents (F Hildebrandt \& Otto, 2005). At first, Hildebrandt et al. found homozygous deletion of Mall and NPHP1 genes in 16 out of 22 families with nephropathy, suggesting a relationship between nephronophthisis and 2q13 (F. Hildebrandt et al., 1997). This could be explained by interchromosomal or intrachromosomal mispairing of the genome inverted repeat, followed by an interchromosomal unequal crossover event (Saunier et al., 2000). In addition to NPHP, Cogan-type congenital ocular motor apraxia (COMA), retinitis pigmentosa (Senior-Loken syndrome), and Joubert syndrome were also found in patients with a deletion of theNPHP1 gene (Betz et al., 2000; Caridi et al., 1998; Parisi et al., 2004).

However, deletion of the proximal region of 2q13 involving RGPD5,RGPD6 , and LIMS3 genes has not been reported. Ciccarelli et al. found that genomic rearrangement of $R A N B P 2$ and GCC2genes on chromosome 2 of primates produced 8 RGPD genes, including RGPD5, RGPD6, and RGPD8 (Ciccarelli et al., 2005).LIMS3 encodes a conserved protein containing the LIM domain, which plays a role in cell-cell and cell-matrix adhesion in the formation of multi-protein complexes. MALL is a member of the MyD88 adapter-like (Mal) family, which functions in a variety of tumors (Marazuela \& Alonso, 2004).

\section{The duplication of the proximal region of $2 q 13$}

Previous studies have shown that duplication of the 2q13 proximal region is commonly associated with autism spectrum disorder (ASD). Baris et al. reported a single-copy gain in the NPHP1 gene in patients with speech delay, global developmental delay, attention hyperactivity disorder (AHDH), and veformities of varying degrees (Baris et al., 2006). Previous reports also found some cases of 2q13 duplication associated with ASD, DD, and mental retardation (ID) (Kaminsky et al., 2011; Yasuda et al., 2014). Similarly, two brothers with ASD were reported. Both brothers had 2q13 duplication, including MALL ,NPHP1 , RGPD6 , and BUB1 genes, and both suffer from ID and liver disorder (Chen et al., 2017). It is clear that duplication of the 2q13 proximal region increases the risk of ASD.

The duplication of the distal region of $2 q 13$ 
Although the penetrance of duplication is lower than that of deletion (H. E. Yu et al., 2012). Duplications at the distal region of $2 \mathrm{q} 13$ are increasingly accepted as risk factors for developmental delay, autism, adult neuropsychiatric expression, and deformities (Costain et al., 2014; Rudd et al., 2009; H. Yu et al., 2012).

Rudd et al. reported that two patients with patrilineal 2q13 had dental crowding (Rudd et al., 2009), while $F B L N 7$ plays a crucial role in odontoblast differentiation and maintenance, as well as in dentine formation (de Vega et al., 2007). Another gene in the region,BUB1, belongs to a family of genes that encodes proteins that bind to the kinetochore, and $B U B 1$ is a vital component of the spindle checkpoint. Tang et al. also demonstrated the role of $h B U B 1$ in centromeric cohesion during mitosis in mammalian cells (Tang, Sun, Harley, Zou, \& Yu, 2004). There are three isoforms ofBCL2L11, which sense apoptotic stimuli and initiate apoptosis by activating BAK, BAX, and other multi-domain pro-apoptotic proteins (O'Connor et al., 1998; Willis et al., 2005). ANAPC1 is the largest subunit of anaphase-promoting complex/cyclosome (APC/C) and ANAPC1 deficiency is the cause of Rothmund-Thomson syndrome type 1 (Ajeawung et al., 2019). Homozygous mutations in MERTK , a tyrosine kinase, are associated with retinal dystrophy and retinitis pigmentosa (Thompson et al., 2002).

\section{Cases}

Six fetuses in our study showed deletion or duplication at a different region of $2 q 13$ on the CMA results. Fetus 1-5 was a deletion or duplication of the proximal region of $2 q 13$, and fetus 6 was a duplication of the distal region of 2q13. Among them, four fetuses had the same breakpoint, which could be considered a 2q13 recurrent breakpoint. The deletions of fetuses 1 and 3 were inherited from their mother. The deletion of fetus 3 was identical to that of his mother, while the deletion of fetus 1 was smaller than that of her mother. Both the deletion of fetus 2 and the duplication of fetus 5 are inherited from the father. The deletion of fetus 2 is identical to her father, and the termination site of fetus 5 is slightly different from her father.

Although, almost all pathogenic CNVs have two characteristics: variable expression and incomplete penetrance, which implies a series of phenotypic outcomes and unaffected family members carrying the same CNV (Deak, Horn, \& Rehder, 2011). To date, many 2q13 deletions and duplications have been hereditary, but parental phenotypes have been poorly described. Half of the six fetuses were at high risk for Down syndrome, and four mothers in this study had a history of abnormal pregnancy-labor. Fetus 1 was accompanied by fetal growth restriction (FGR), and the mother had given birth to two boys who both died of neuroblastoma or intracranial hemorrhage. The mother of fetus 2 had a spontaneous abortion due to the termination of the embryo. Fetus 2 was found to have strong echoes in the left ventricle and bowel.LISM3 is involved in cell-cell and cell-matrix adhesion processes and is involved in cytoskeleton regulation. However, molecules that regulate cell migration and cell adhesion are thought to be involved in congenital heart defect (CHD) (Sailani et al., 2013). The deletion of fetus 3 is inherited from the mother. The mother of fetus 3 had three pregnancies, including one induced labor due to "cleft lip and cleft palate" and one spontaneous abortion due to fetal termination, while fetus 3 was accompanied by Xp22 subtelomere microduplication. It is widely accepted that subtelomere chromosome rearrangement may be a common cause of idiopathic mental retardation (MR) (Hélias-Rodzewicz et al., 2002). The genotypes of aborted fetuses cannot be determined, but chromosomal abnormalities may play a role in early pregnancy loss. Deletion of 2q13 also occurs in fetus 4; congenital hydrocephalus and congenital pulmonary cystadenomatous were found after birth. Fetus 5 was born to elderly parents. It is believed that elderly parturient women have a higher incidence of chromosomal abnormalities than younger mothers (Gou et al., 2020). Furthermore, MLPA results showed an abnormal copy number of the $S M N$ gene in fetal 1, 3, and 6, which is the primary pathogenic gene of spinal muscular atrophy (SMA) (Lefebvre et al., 1995).

\section{CONCLUSIONS}

The presence of a chromosomal-specific low-copy repeat sequence (LCR) increases the risk of chromosomal rearrangement and makes chromosome 2 susceptible to many unbalanced structural variants, including deletions and duplications. These CNVs can be developed de novo or inherited from parents with similar deletions or duplications. However, almost all CNVs have two characteristics of variable expression and incomplete 
penetrance, and patients with the same CNV may have different phenotypes or be unaffected (Deak et al., 2011; Rosenfeld, Coe, Eichler, Cuckle, \& Shaffer, 2013), and the penetrance of duplication is lower than that of deletion (H. E. Yu et al., 2012). Therefore, it is necessary to evaluate multiple individuals with the same $\mathrm{CNV}$ to capture characteristic sets associated with genomic diseases.

Of the six fetuses reported here, four had deletions or duplicates inherited from their parents, and they had different phenotypes. The characteristics of variable expression and incomplete penetrance of genomic diseases pose challenges for prenatal diagnosis and genetic counseling. These two characteristics should be explained in detail when providing prenatal genetic counseling to mothers and their families.

\section{ACKNOWLEDGEMENTS}

We sincerely thank the six families for supporting our research.

\section{CONFLICT OF INTEREST}

The author solemnly states that there is no conflict of interest

to be disclosed.

\section{AUTHOR CONTRIBUTIONS}

The corresponding authors are responsible for the study design and revision of the paper. LL and XZH worked together on analyzing the genetic data and drafted the present manuscript. MY, JPC and ZPZ collected clinical information and provided genetic counseling. HG and QYL contributed to the revision of the manuscript. All authors have read and approved the final manuscript.

\section{ETHICS STATEMENT}

This study was conducted in strict accordance with the approval and supervision of the Committee of Shenzhen People's Hospital. All participants provided written informed consent for sample collection and subsequent analyses.

\section{DATA AVAILABILITY STATEMENT}

Data can be made available upon reasonable request to the corresponding author.

\section{References}

Ajeawung, N. F., Nguyen, T. T. M., Lu, L., Kucharski, T. J., Rousseau, J., Molidperee, S., . . Campeau, P. M. (2019). Mutations in ANAPC1, Encoding a Scaffold Subunit of the Anaphase-Promoting Complex, Cause Rothmund-Thomson Syndrome Type 1. Am J Hum Genet, 105 (3), 625-630. doi:10.1016/j.ajhg.2019.06.011

Baris, H., Bejjani, B., Tan, W., Coulter, D., Martin, J., Storm, A., . . Kimonis, V. (2006). Identification of a novel polymorphism-the duplication of the NPHP1 (nephronophthisis 1) gene. American journal of medical genetics. Part A (17), 1876-1879. doi:10.1002/ajmg.a.31390

Betz, R., Rensing, C., Otto, E., Mincheva, A., Zehnder, D., Lichter, P., \& Hildebrandt, F. (2000). Children with ocular motor apraxia type Cogan carry deletions in the gene (NPHP1) for juvenile nephronophthisis. The Journal of pediatrics, 136 (6), 828-831. doi:10.1067/mpd.2000.106225

Caridi, G., Murer, L., Bellantuono, R., Sorino, P., Caringella, D., Gusmano, R., \& Ghiggeri, G. (1998). Renal-retinal syndromes: association of retinal anomalies and recessive nephronophthisis in patients with homozygous deletion of the NPH1 locus. American journal of kidney diseases : the official journal of the National Kidney Foundation, 32 (6), 1059-1062. doi:10.1016/s0272-6386(98)70083-6

Chen, C., Lin, S., Lee, C., Chern, S., Wu, P., Chen, Y., . . . Wang, W. (2017). Recurrent 2q13 microduplication encompassing MALL, NPHP1, RGPD6, and BUB1 associated with autism spectrum disorder, intellectual disability, and liver disorder. Taiwanese Journal of Obstetrics $\mathscr{E}$ Gynecology, 56 (1), 98-101. doi:10.1016/j.tjog.2016.12.003 
Ciccarelli, F. D., von Mering, C., Suyama, M., Harrington, E. D., Izaurralde, E., \& Bork, P. (2005). Complex genomic rearrangements lead to novel primate gene function. Genome Res, 15 (3), 343-351. doi:10.1101/gr.3266405

Costain, G., Lionel, A., Fu, F., Stavropoulos, D., Gazzellone, M., Marshall, C., . . . Bassett, A. (2014). Adult neuropsychiatric expression and familial segregation of $2 \mathrm{q} 13$ duplications. American journal of medical genetics. Part B, Neuropsychiatric genetics : the official publication of the International Society of Psychiatric Genetics (4), 337-344. doi:10.1002/ajmg.b.32236

de Vega, S., Iwamoto, T., Nakamura, T., Hozumi, K., McKnight, D., Fisher, L., . . Yamada, Y. (2007). TM14 is a new member of the fibulin family (fibulin-7) that interacts with extracellular matrix molecules and is active for cell binding. The Journal of biological chemistry, 282 (42), 30878-30888. doi:10.1074/jbc.M705847200

Deak, K., Horn, S., \& Rehder, C. (2011). The evolving picture of microdeletion/microduplication syndromes in the age of microarray analysis: variable expressivity and genomic complexity. Clinics in laboratory medicine, 31 (4), 543-564, viii. doi:10.1016/j.cll.2011.08.008

Dhillon, R. K., Hillman, S. C., Morris, R. K., McMullan, D., Williams, D., Coomarasamy, A., \& Kilby, M. D. (2014). Additional information from chromosomal microarray analysis (CMA) over conventional karyotyping when diagnosing chromosomal abnormalities in miscarriage: a systematic review and meta-analysis. BJOG, 121 (1), 11-21. doi:10.1111/1471-0528.12382

Feuk, L., Carson, A. R., \& Scherer, S. W. (2006). Structural variation in the human genome. Nat Rev Genet, 7 (2), 85-97. doi:10.1038/nrg1767

Giglio, S., Broman, K., Matsumoto, N., Calvari, V., Gimelli, G., Neumann, T., . . Zuffardi, O. (2001). Olfactory receptor-gene clusters, genomic-inversion polymorphisms, and common chromosome rearrangements. American journal of human genetics, 68 (4), 874-883. doi:10.1086/319506

Gou, L., Liu, T., Wang, Y., Wu, Q., Hu, S., Dong, B., . . Gu, M. (2020). Clinical utilization of chromosomal microarray analysis for the genetic analysis in subgroups of pregnancy loss. J Matern Fetal Neonatal Med, 1-8. doi:10.1080/14767058.2020.1849126

Hélias-Rodzewicz, Z., Bocian, E., Stankiewicz, P., Obersztyn, E., Kostyk, E., Jakubów-Durska, K., . . - Mazurczak, T. (2002). Subtelomeric rearrangements detected by FISH in three of 33 families with idiopathic mental retardation and minor physical anomalies. Journal of Medical Genetics, 39 (9), e53. doi:10.1136/jmg.39.9.e53

Hildebrandt, F., \& Otto, E. (2005). Cilia and centrosomes: a unifying pathogenic concept for cystic kidney disease? Nature reviews. Genetics, 6 (12), 928-940. doi:10.1038/nrg1727

Hildebrandt, F., Otto, E., Rensing, C., Nothwang, H. G., Vollmer, M., Adolphs, J., . . Brandis, M. (1997). A novel gene encoding an SH3 domain protein is mutated in nephronophthisis type 1. Nat Genet, 17 (2), 149-153. doi:10.1038/ng1097-149

Kaminsky, E., Kaul, V., Paschall, J., Church, D., Bunke, B., Kunig, D., . . Martin, C. (2011). An evidencebased approach to establish the functional and clinical significance of copy number variants in intellectual and developmental disabilities. Genetics in medicine : official journal of the American College of Medical Genetics, 13 (9), 777-784. doi:10.1097/GIM.0b013e31822c79f9

Lefebvre, S., Bürglen, L., Reboullet, S., Clermont, O., Burlet, P., Viollet, L., . . . Zeviani, M. (1995). Identification and characterization of a spinal muscular atrophy-determining gene.Cell, 80 (1), 155-165. doi:10.1016/0092-8674(95)90460-3

Marazuela, M., \& Alonso, M. (2004). Expression of MAL and MAL2, two elements of the protein machinery for raft-mediated transport, in normal and neoplastic human tissue. Histology and histopathology, 19 (3), 925-933. doi:10.14670/hh-19.925 
Miller, D. T., Adam, M. P., Aradhya, S., Biesecker, L. G., Brothman, A. R., Carter, N. P., . . . Ledbetter, D. H. (2010). Consensus statement: chromosomal microarray is a first-tier clinical diagnostic test for individuals with developmental disabilities or congenital anomalies.Am J Hum Genet, 86 (5), 749-764. doi:10.1016/j.ajhg.2010.04.006

O'Connor, L., Strasser, A., O'Reilly, L., Hausmann, G., Adams, J., Cory, S., \& Huang, D. (1998). Bim: a novel member of the Bcl-2 family that promotes apoptosis. The EMBO journal, 17 (2), 384-395. doi:10.1093/emboj/17.2.384

Parisi, M., Bennett, C., Eckert, M., Dobyns, W., Gleeson, J., Shaw, D., . . Glass, I. (2004). The NPHP1 gene deletion associated with juvenile nephronophthisis is present in a subset of individuals with Joubert syndrome. American journal of human genetics, 75 (1), 82-91. doi:10.1086/421846

Rosenfeld, J., Coe, B., Eichler, E., Cuckle, H., \& Shaffer, L. (2013). Estimates of penetrance for recurrent pathogenic copy-number variations. Genetics in medicine : official journal of the American College of Medical Genetics, 15 (6), 478-481. doi:10.1038/gim.2012.164

Rudd, M., Keene, J., Bunke, B., Kaminsky, E., Adam, M., Mulle, J., . . Martin, C. (2009). Segmental duplications mediate novel, clinically relevant chromosome rearrangements. Human molecular genetics, 18 (16), 2957-2962. doi:10.1093/hmg/ddp233

Sailani, M., Makrythanasis, P., Valsesia, A., Santoni, F., Deutsch, S., Popadin, K., . . Antonarakis, S. (2013). The complex SNP and CNV genetic architecture of the increased risk of congenital heart defects in Down syndrome. Genome research, 23 (9), 1410-1421. doi:10.1101/gr.147991.112

Saunier, S., Calado, J., Benessy, F., Silbermann, F., Heilig, R., Weissenbach, J., \& Antignac, C. (2000). Characterization of the NPHP1 locus: mutational mechanism involved in deletions in familial juvenile nephronophthisis. American journal of human genetics, 66 (3), 778-789. doi:10.1086/302819

Shaw, C. J., \& Lupski, J. R. (2004). Implications of human genome architecture for rearrangement-based disorders: the genomic basis of disease. Hum Mol Genet, 13 Spec No 1, R57-64. doi:10.1093/hmg/ddh073

Tang, Z., Sun, Y., Harley, S., Zou, H., \& Yu, H. (2004). Human Bub1 protects centromeric sister-chromatid cohesion through Shugoshin during mitosis. Proceedings of the National Academy of Sciences of the United States of America, 101 (52), 18012-18017. doi:10.1073/pnas.0408600102

Thompson, D., McHenry, C., Li, Y., Richards, J., Othman, M., Schwinger, E., . . Gal, A. (2002). Retinal dystrophy due to paternal isodisomy for chromosome 1 or chromosome 2, with homoallelism for mutations in RPE65 or MERTK, respectively. American journal of human genetics, 70 (1), 224-229. doi:10.1086/338455

Wenger, S., Bleigh, O., \& Hummel, M. (2004). Cleft palate in a newborn with duplication 2(q13q23). The Cleft palate-craniofacial journal : official publication of the American Cleft Palate-Craniofacial Association, 41 (5), 568-570. doi:10.1597/03-059.1

Willis, S., Chen, L., Dewson, G., Wei, A., Naik, E., Fletcher, J., . . Huang, D. (2005). Proapoptotic Bak is sequestered by Mcl-1 and Bcl-xL, but not Bcl-2, until displaced by BH3-only proteins. Genes 85 development, 19 (11), 1294-1305. doi:10.1101/gad.1304105

Yasuda, Y., Hashimoto, R., Fukai, R., Okamoto, N., Hiraki, Y., Yamamori, H., . . . Takeda, M. (2014). Duplication of the NPHP1 gene in patients with autism spectrum disorder and normal intellectual ability: a case series. Annals of general psychiatry, 13 , 22. doi:10.1186/s12991-014-0022-2

Yu, H., Hawash, K., Picker, J., Stoler, J., Urion, D., Wu, B., \& Shen, Y. (2012). A recurrent 1.71 Mb genomic imbalance at 2q13 increases the risk of developmental delay and dysmorphism. Clinical genetics, 81 (3), 257-264. doi:10.1111/j.1399-0004.2011.01637.x

Yu, H. E., Hawash, K., Picker, J., Stoler, J., Urion, D., Wu, B. L., \& Shen, Y. (2012). A recurrent 1.71 Mb genomic imbalance at 2q13 increases the risk of developmental delay and dysmorphism. Clin Genet, 81 (3), 
257-264. doi:10.1111/j.1399-0004.2011.01637.x

Table 1 Clinical data.

\begin{tabular}{|c|c|c|c|c|c|c|}
\hline Fetus & 1 & 2 & 3 & 4 & 5 & 6 \\
\hline Mother's age & 29 & 29 & 31 & 29 & 43 & 30 \\
\hline Sample type & Cord blood & Cord blood & Cord blood & $\begin{array}{l}\text { Amniotic } \\
\text { fluid }\end{array}$ & Cord blood & $\begin{array}{l}\text { Amniotic } \\
\text { fluid }\end{array}$ \\
\hline $\begin{array}{l}\text { Gestational } \\
\text { weeks }\end{array}$ & $18+$ & $22+$ & $25+$ & $19+$ & $22+$ & $20+$ \\
\hline MLPA & $\begin{array}{l}\text { duplication } \\
\text { of exon } 8 \text { of } \\
\text { the SMN1; } \\
\text { heterozy- } \\
\text { gous } \\
\text { deletions of } \\
\text { exon } 8 \text { of } \\
\text { the SMN2 }\end{array}$ & $\mathrm{N}$ & $\begin{array}{l}\text { heterozygous } \\
\text { deletions of } \\
\text { exon } 7 \text { and } \\
\text { exon } 8 \text { of } \\
\text { the SMN2; } \\
\text { duplication } \\
\text { of terminal } \\
\text { subtelomeres } \\
\text { of PAR } \\
\text { region of } \\
\text { Xp22 }\end{array}$ & $\mathrm{N}$ & $\mathrm{N}$ & $\begin{array}{l}\text { duplication } \\
\text { of exon } 7 \\
\text { and exon } 8 \\
\text { of the } \\
\text { SMN1; het- } \\
\text { erozygous } \\
\text { deletions of } \\
\text { exon } 7 \text { and } \\
\text { exon } 8 \text { of } \\
\text { the SMN2 }\end{array}$ \\
\hline $\operatorname{AFP}(\mathrm{MoM})$ & 2.01 & 1.23 & 0.77 & 0.58 & 0.89 & 0.67 \\
\hline $\begin{array}{l}\text { Free } \beta \text { - } \\
\text { hCG }(\mathrm{MoM})\end{array}$ & 7.16 & 2.46 & 0.9 & 2.63 & 2.177 & 2.87 \\
\hline $\mathrm{uE} 3(\mathrm{MoM})$ & 0.47 & 1.14 & 0.732 & 0.64 & 1.443 & 0.26 \\
\hline Ds risk & $1 / 10000$ & $1 / 4868$ & $1 / 473$ & $1 / 250$ & $1 / 65$ & $1 / 204$ \\
\hline NTD & Low risk & Low risk & Low risk & $\mathrm{U}$ & $\mathrm{U}$ & Low risk \\
\hline $\begin{array}{l}\text { Clinical } \\
\text { diagnosis }\end{array}$ & FGR & $\begin{array}{l}\text { bowel strong } \\
\text { echo and left } \\
\text { ventricular } \\
\text { strong echo }\end{array}$ & $\mathrm{N}$ & $\begin{array}{l}\text { left ventricle } \\
\text { punctate } \\
\text { strong echo }\end{array}$ & $\begin{array}{l}\text { Elderly } \\
\text { couple, two } \\
\text { renal pelvis } \\
\text { dissection in } \\
\text { the fetus }\end{array}$ & $\mathrm{N}$ \\
\hline $\begin{array}{l}\text { Abnormal } \\
\text { pregnancy- } \\
\text { labor history } \\
\text { of mother }\end{array}$ & $\begin{array}{l}\text { gave birth to } \\
\text { two boys who } \\
\text { died in infancy }\end{array}$ & $\begin{array}{l}\text { one } \\
\text { spontaneous } \\
\text { abortion }\end{array}$ & $\begin{array}{l}\text { one induced } \\
\text { labor due to } \\
\text { "cleft lip and } \\
\text { cleft palate" } \\
\text { and one } \\
\text { spontaneous } \\
\text { abortion due } \\
\text { to fetal } \\
\text { termination }\end{array}$ & $\mathrm{N}$ & $\begin{array}{l}\text { two induced } \\
\text { abortions }\end{array}$ & $\mathrm{N}$ \\
\hline
\end{tabular}

Abbreviations: MPLA, multiplex ligation-dependent probe amplification; AFP, alpha-fetoprotein (Normal range: 0.61-2.49); Free $\beta$-hCG, free beta-human chorionic gonadotropin (0.41-2.39); uE3, unconjugated estriol (>0.73); MoM, multiple of median; DS, Down syndrome (Normal range: $<1 / 1000$ ); NTD, neural tube defects; FGR, fetal growth restriction; U, unknown; N, normal.

\begin{tabular}{lllllll}
\hline Case & 1 & 2 & 3 & 4 & 5 & 6 \\
\hline Gestational weeks & 40 & 39 & 36 & 39 & 38 & 38 \\
Delivery situation & Caesarean section & Normal delivery & Caesarean section & Caesarean section & Caesarean section & N
\end{tabular}




\begin{tabular}{lllllll}
\hline Case & 1 & 2 & 3 & 4 & 5 & 6 \\
\hline Sex of the baby & Girl & Girl & Boy & Boy & Girl & B \\
Weight $(\mathrm{g})$ & 3000 & 3130 & 2800 & 3450 & 3500 & 30 \\
Height $(\mathrm{cm})$ & 50 & 49 & 49 & 50 & 50 & 50 \\
\hline
\end{tabular}

Table 2 Pregnancy outcome

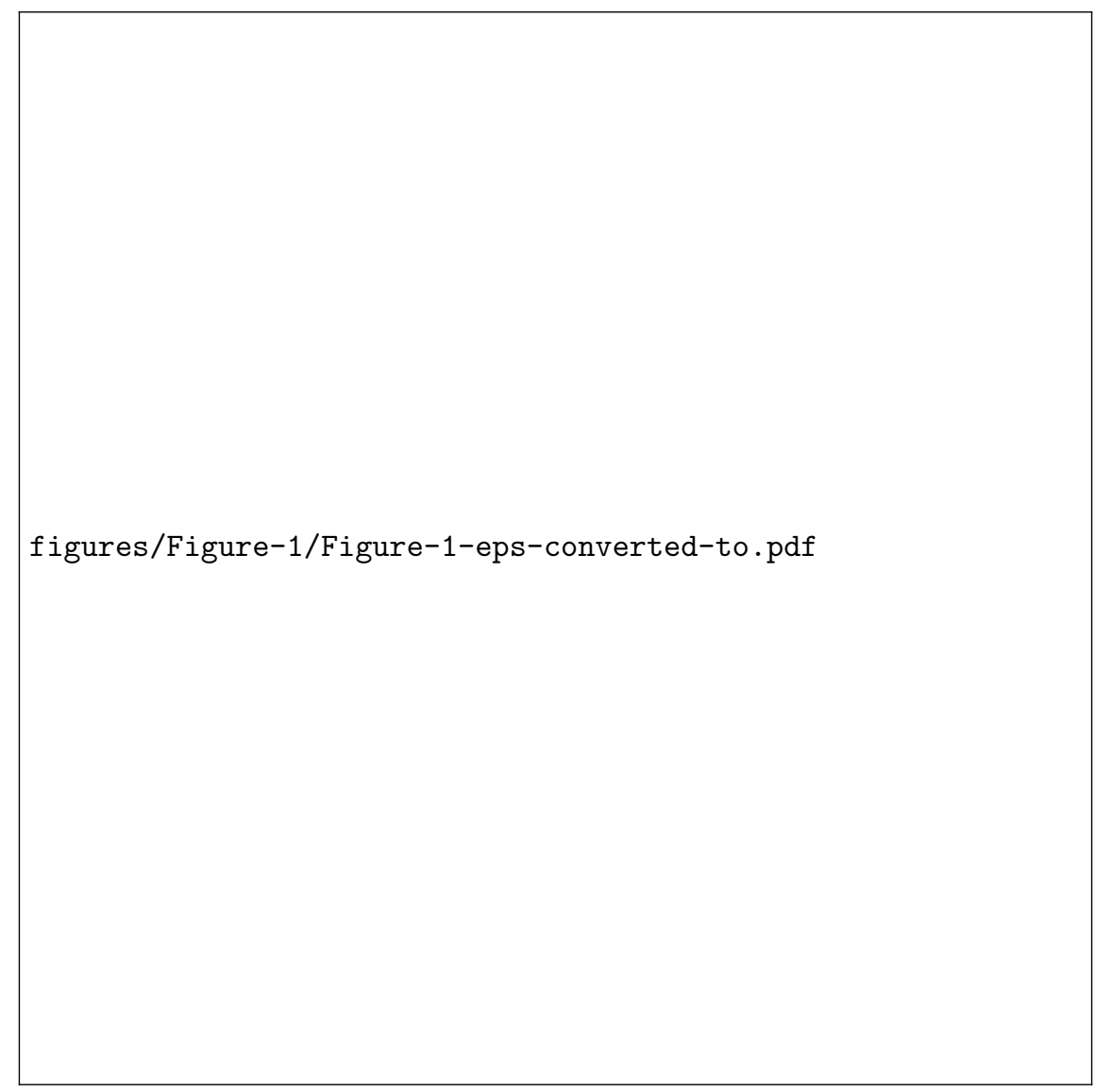


figures/Figure-2/Figure-2-eps-converted-to.pdf 